\title{
Modern Theory of Gear Meshing without Considering the Geometry of the Instrument
}

\author{
A. Pournaras
}

\author{
Technical University of Gabrovo, Bulgaria
}

Received 29 November 2016; Accepted 11 February 2017

\begin{abstract}
The contemporary classic theory of gearing is realized through the instrument needed for production of the toothed wheels of the gear. By means of the proposed relationships in the present report, it is proposed that all instrumental limits are eliminated and that free geometric synthesis to realized by observing the principles of Olivier and basic theorem of Zalgaller-Litvin. The work compares both synthesis methods - the classic and the contemporary one - while discovering some not yet used opportunities for geometric synthesis of involute cylindrical gears in accordance with preset qualitative parameters.
\end{abstract}

Keywords: free geometric synthesis, involute cylindrical gears

\section{Introduction}

The synthesis of involute cylindrical gears in generalized parameters gives a new "modernized" approach that allows $[1,2,3,4$,$] : the involute profile of the gear tooth to be seen as$ compound; analysis of the gear tooth profile without taking into account the geometry of the instrument.

This method of synthesis uses the following base hypotheses: hypothetically, there exists a theoretical point of intersection of two involutes, called, by prof. Vulgakov, "sharpening point", even when the thickness of the gear tooth on the peak circumference is non-zero; the gear teeth don't have transition curves because the synthesis is performed without an instrument and are called "teeth"; the notion of radial clearance in the meshing does not exist; the notion of interference between joint working gear profiles does not exist, because the whole theoretical gear profile near the base circumference is being used; gear teeth have a permanent, previously adopted, thickness on the pitch circumference;

\section{Modern Theory of Gear Meshing without Considering the Geometry of the Instrument}

The summary parameters $\Delta_{1,2}$ are known in advance and at a non-zero gear tooth thickness are determined by:

$$
\operatorname{inv} \Delta_{1,2}=v_{a_{1,2}} \cdot \cos \alpha_{a_{1,2}}+i n v \alpha_{a_{1,2}}
$$

where $\alpha_{a 1,2}$ are the angles of the involutes on the pitch circumference;

$v_{\mathrm{a} 1,2}$ - the relative thicknesses of the gear teeth on the pitch circumference, determined by:

E-mail address: aziez.mednadjib@yahoo.fr

ISSN: $1791-2377$ @ 2017 Eastern Macedonia and Thrace Institute of Technology. All rights reserved.

$$
v_{a_{1,2}}=\frac{S_{a_{1,2}}}{d_{b_{1,2}}}=\frac{(0,25 \div 0,5)}{z_{1,2} \cdot \cos \alpha},
$$

where

$\mathrm{z}_{1,2}$ are the number of the teeth on the gear wheels;

$\mathrm{S}_{\mathrm{a} 1,2}$ - the thicknesses of teeth for the corresponding wheels on the circumference;

$\mathrm{d}_{\mathrm{b} 1,2}$ - diameters of the corresponding base circles;

$\alpha$ - the profile angle of the output outline.

Since the tooth thickness at the tip is being set, then with an accuracy of $\sec \alpha$, at a standard value of the profile angle of the output outline, in [2,3] the upper limit of the thickness expands to:

$$
\frac{1}{4 \cdot z_{1,2}} \leq v_{a_{1,2}} \leq \frac{1}{1,5 \cdot z_{1,2}},
$$

Using the predefined, generalized parameters, the angle of meshing $\alpha_{w}$ and the frontal overlap coefficient $\varepsilon_{\alpha}$ are being formally defined.

This innovative approach of input of generalized parameters allows subsequently the creation of the geometric synthesis of the involute gear tooth that has two different involutes. For the first time, this variationof the involute profile is proposed and implemented in [3], as the following possibilities of forming are being defined (Figure 1).

According to figure 1 in the method of generalized parameters, a physical defect of the theory appears. This defect multiplies two separate occasions due to the need of defining independent variables for the other profile as well. This defect results in the need of an "initial" symmetry axis of the gear tooth on which the "coupling" of the two compound profiles is being carried out. 


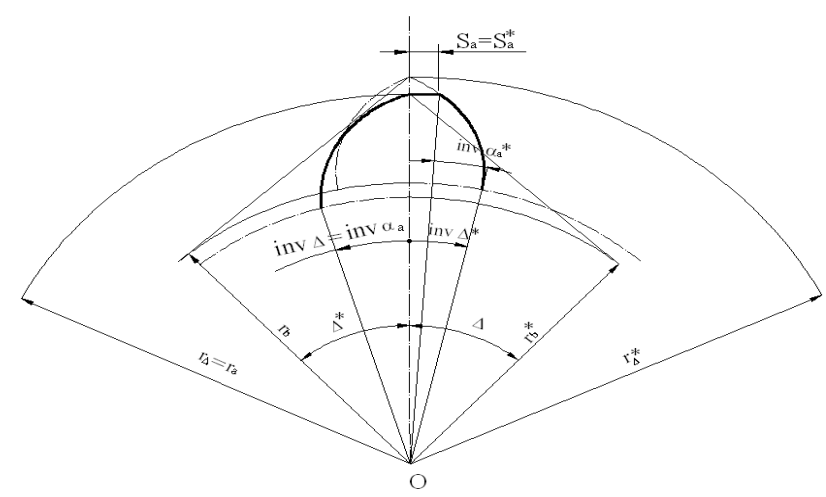

a)

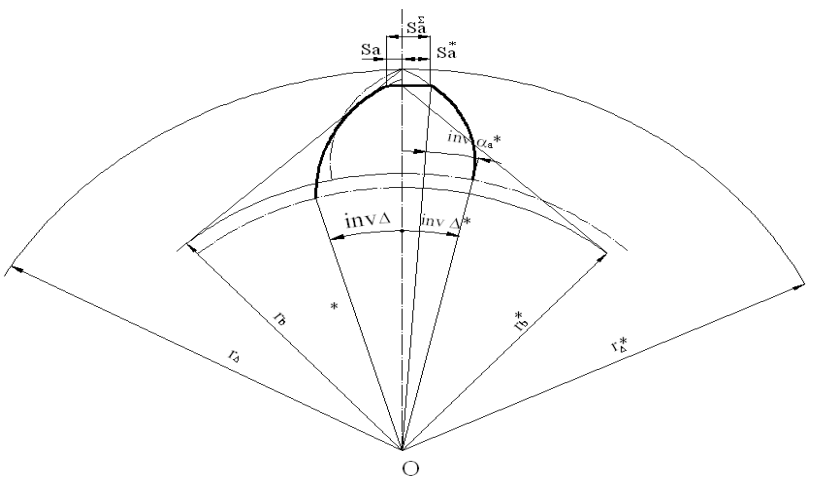

b)

Fig. 1. Forming of asymmetric profile in generalized parameters: a) borderline forming case $b$ ) general forming case

Therefore, the hypothesis of the existence of a theoretical sharpening point of the involutes, which is cited as an advantage by the author of this theory, became one significant disadvantage. Beyond this initial symmetry axis, it is impossible to define the independent variables, wherein their number is not doubled, because one of them becomes dependent. Thus the asymmetric profile is impossible and it is extremely wrong to be interpreted as consisting of only two symmetrical profiles. This makes the fundamental law of meshing during the collaboration of the gear wheels. If the asymmetric profile consists of two symmetrical profiles, then each one of them must exist independently of the other, as well as jointly.

Dependencies that serve to determine the rest of the geometric parameters of the gear are:

$$
\mid \begin{aligned}
& \operatorname{inv} \alpha_{w}=\frac{z_{2} \cdot \operatorname{inv} \Delta_{2} \pm z_{1} \cdot \operatorname{inv} \Delta_{1}-0,5 \cdot \pi}{z_{2} \pm z_{1}} \\
& \frac{\cos \alpha}{\cos \alpha_{w}}=\frac{\cos \alpha^{*}}{\cos \alpha_{w}^{*}} ; \frac{\cos \alpha}{\cos \alpha_{a_{1,2}}}=\frac{\cos \alpha^{*}}{\cos \alpha_{a_{1,2}}^{*}}
\end{aligned}
$$

where $\alpha_{\mathrm{w}}$ and $\alpha_{\mathrm{w}}{ }^{*}$ are the angles of meshing of the two compound parts of the asymmetric profile.

According to (4) the symbol "+" refers to external meshing, and the symbol "-" for internal meshing. This physical limitation that exists in the theory of generalized parameters is interpreted from another position by introducing an additional parity between the diameters of sharpening of the compound involutes (Fig. 2):

$$
d_{\Delta_{1,2}}=d_{\Delta_{1,2}^{*}}^{*}
$$

Based on the adopted additional restriction, the number of independent variables is reduced, because the asymmetric gear tooth profile is being released by the "initial" symmetry axis, which is transformed into another axis.

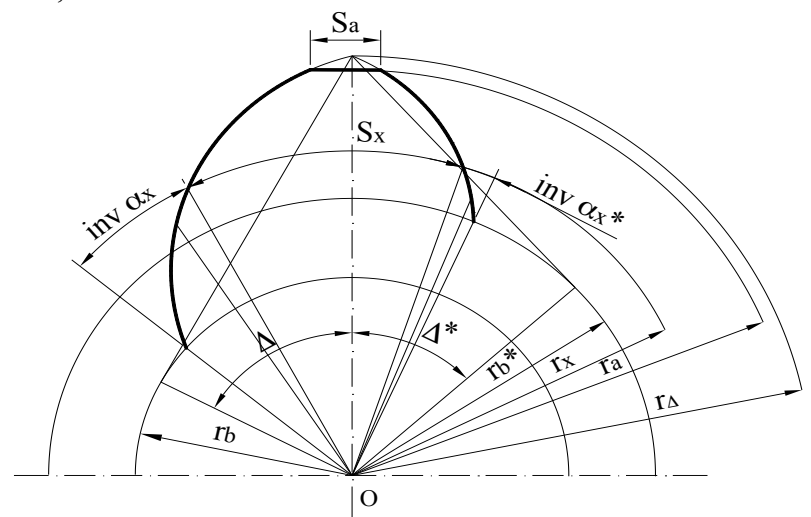

Fig. 2. Another possibility for the forming of an asymmetrical gear tooth profile

The dependencies, which serve to determine the other geometric parameters of the gear are:

$$
\begin{aligned}
& \mid i n v \alpha_{w}^{*}+i n v \alpha_{w}=\frac{z_{2} \cdot\left(i n v \Delta_{2}+i n v \Delta_{2}^{*}\right)}{z_{2} \pm z_{1}} \pm \\
& \frac{z_{1} \cdot\left(\operatorname{inv} \Delta_{1}+\operatorname{inv} \Delta_{1}^{*}\right)-2 \cdot \pi}{z_{2} \pm z_{1}} \\
& \frac{\cos \alpha}{\cos \alpha_{w}}=\frac{\cos \alpha^{*}}{\cos \alpha_{w}^{*}} \\
& \frac{\cos \alpha}{\cos \Delta_{1}}=\frac{\cos \alpha^{*}}{\cos \Delta_{1}^{*}}
\end{aligned}
$$

System (6) implies a mandatory condition between the angles of sharpening only for one of the gear whees. From here follows that $\Delta^{*}{ }_{2}$ is also a dependent variable, which limits the possibilities for a geometric synthesis in generalized parameters.

This implies the need for an additional dependency in the system (6), which removes the restriction on the presence of a predetermined axis.

In case of an incline of the teeth $\beta$ of the gear wheels, the number of independent variables $\Delta_{\beta}$ and $\Delta^{*}{ }_{\beta}$ increases. They characterize the additional coefficient of overlapping $\varepsilon_{\beta}$ and $\varepsilon^{*}{ }_{\beta}$ in the frontal section for both teeth parts:

$$
\begin{aligned}
& \Delta_{\beta_{1,2}}=\operatorname{arctg}\left(\frac{2 \cdot b_{1,2}}{d_{b_{1,2}}} \cdot \operatorname{tg} \beta\right), \\
& \Delta_{\beta_{1,2}}^{*}=\operatorname{arctg}\left(\frac{2 \cdot b_{1,2}}{d_{b_{1,2}}^{*}} \cdot \operatorname{tg} \beta\right)
\end{aligned}
$$

where $b_{1,2}$ is the width of the wheel 1 and 2 in the gear.

The researches, made by prof. Vulgakov, contain no solution to the problem with the interference between opposite involutes within the wheel (Fig. 3). Therefore, in 
$[1,2]$, it is unjustifiedly recommended with the increase of one of the angles of the output outline, to decrease the other, which provides a "reserve" against the existence of such interference.

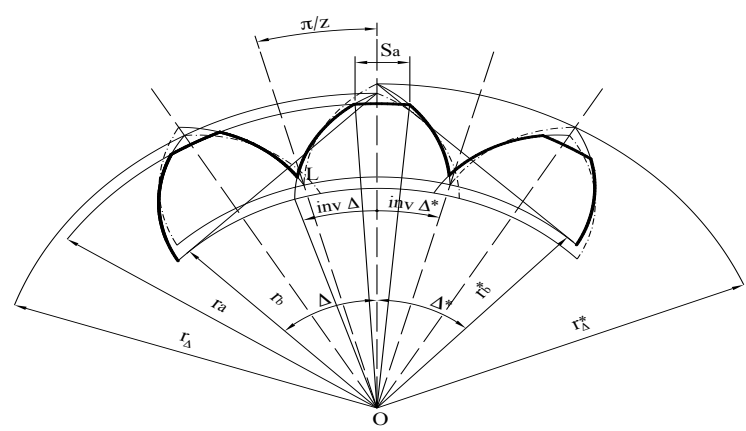

Fig. 3. Interference between opposite involutes, within the gear

Having larger than standard profile angles of the output outline creates a condition for the existence of a common point L (Fig. 3) between the opposite involutes, which prevents the selection of independent variables for the other gear wheel. This implies a physical limitation in their choices, because the new point $\mathrm{L}$ restricts the height of the teeth, and this contradicts the hypotheses that were originally made.

The condition for mutual interference of the two opposite profiles is obtained after a study of the arc of the tooth space $\left(\mathrm{e}_{\mathrm{L} 1,2}\right)$ and determining the common intersection point between the opposite involutes:

$\vartheta_{L_{1,2}}=\frac{P_{L_{1,2}}+P_{L_{1,2}}^{*}}{2}-\frac{S_{L_{1,2}}+S_{L_{1,2}}^{*}}{2}$,

where $\mathrm{P}_{\mathrm{L} 1,2}$ and $\mathrm{P}_{\mathrm{L} 1,2}^{*}$ are the circumference steps of the opposite profiles of the circumference that passes through the intersection point $\mathrm{L}_{1,2}$, for both gear wheels:

$$
\begin{aligned}
& P_{L_{1,2}}=\frac{\pi}{z_{1,2}} \cdot \frac{d_{b_{1,2}}}{\cos \alpha_{L_{1,2}}}, \\
& P_{L_{1,2}}^{*}=\frac{\pi}{z_{1,2}} \cdot \frac{d_{b_{1,2}}^{*}}{\cos \alpha_{L_{1,2}}^{*}}
\end{aligned}
$$

$\mathrm{S}_{\mathrm{L} 1,2}$ and $\mathrm{S}_{\mathrm{L} 1,2}^{*}$ - the thicknesses of the profiles on the intersection circumference:

$$
\begin{aligned}
& S_{L_{1,2}}=\left(i n v \Delta_{1,2}-i n v \alpha_{L_{1,2}}\right) \frac{d_{b_{1,2}}}{\cos \alpha_{L_{1,2}}}, \\
& S_{L_{1,2}}^{*}=\left(i n v \Delta_{1,2}^{*}-i n v \alpha_{L_{1,2}}^{*}\right) \frac{d_{b_{1,2}^{*}}^{*}}{\cos \alpha_{L_{1,2}}^{*}},
\end{aligned}
$$

After substitution of the expressions (9) and (10) in the expression (8), and subsequent processing, the following transcendent system for determining the angles of the involutes in the intersection of $\mathrm{L}$ is obtained:

$$
\begin{aligned}
& \operatorname{inv} \alpha_{L_{1,2}}+i n v \alpha_{L_{1,2}}^{*}=i n v \Delta_{1,2}+i n v \Delta_{1,2}^{*}-\frac{2 \cdot \pi}{z_{1,2}} \\
& \alpha_{L_{1,2}}^{*}=\arccos \left(\frac{\cos \alpha^{*}}{\cos \alpha} \cdot \cos \alpha_{L_{1,2}}\right)
\end{aligned},
$$

The transcendental system (11) is solved by the method of successive approximations to a preset accuracy in the following dependency:

$$
\begin{gathered}
\alpha_{L 1,2(n+1)}=\alpha_{L_{1,2(n)}}- \\
-\frac{\operatorname{inv} \alpha_{L_{1,2}}+i n v \alpha_{L_{1,2}}^{*}}{\operatorname{tg}^{2} \alpha_{L_{1,2}}+\operatorname{tg}^{2}\left(\arccos \left(\frac{\cos \alpha^{*}}{\cos \alpha} \cdot \cos \alpha_{L_{1,2}}\right)\right)}+, \\
+\frac{\left(2 \cdot \pi / z_{1,2}\right)-i n v \Delta_{1,2}-i n v \Delta_{1,2}^{*}}{\operatorname{tg}^{2} \alpha_{L_{1,2}}+\operatorname{tg}^{2}\left(\arccos \left(\frac{\cos \alpha^{*}}{\cos \alpha} \cdot \cos \alpha_{L_{1,2}}\right)\right)}
\end{gathered}
$$

Interference of opposite profiles occurs at:

$$
\mid \begin{aligned}
& \alpha_{p_{1,2}}-\alpha_{L_{1,2}}=0 \\
& \alpha_{p_{1,2}}^{*}-\alpha_{L_{1,2}}^{*}=0
\end{aligned},
$$

And the following additional condition

$$
\left(\operatorname{inv} \Delta_{1,2}+\operatorname{inv} \Delta_{1,2}^{*}\right)>\frac{2 . \pi}{z_{1,2}},
$$

where $\alpha_{\mathrm{pl}, 2}$ and $\alpha_{\mathrm{p} 1,2}^{*}$ are the angles of the involutes in their lower active points.

Only during implementation of conditions (13) and (14) is it possible to have a free choice of profile angles of the instrument and to implement the "free geometric synthesis" in generalized parameters.

The solution for this problem is proposed by the author of this research for academic rank.

The physical meaning of this new interference in generalized parameters consists in the presence of an "initial" symmetry axis of the tooth space, which differs from that of the tooth, i. e., the angle between them is other than $(\pi / \mathrm{z})$, when the condition (14) is met.

\section{Conclusions}

From figure 1.4 it follows that the areas of existence in generalized parameters provide:

- the possibility for extrapolating the isolines, characterizing the quality indicators of meshing for one profile on top of the other, i.e., using an area of existence, composed of two sub-areas;

the isoline $\alpha_{\mathrm{a} 2}^{*}=\Delta_{2}^{*}$ is limiting for this method of synthesis. In fact, the asymmetric involute profile continues to exist close to the isoline of zero thickness of the tooth on the pitch circumference $S_{a 2}=0$, but it is impossible to define the independent and dependent variables. 


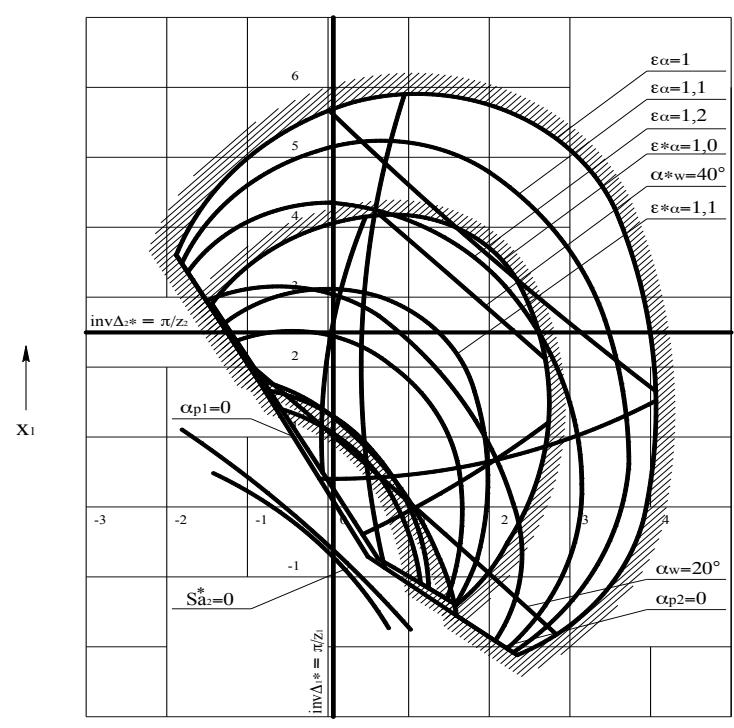

$\mathrm{x}_{2} \longrightarrow$

Fig. 4. Unconditional area of existence for the output reverse gear with initial parameters:a) $\alpha=\alpha^{*}=30^{\circ}$ in system with coordinates $\Delta_{1}, \Delta_{1}{ }^{*}, \Delta_{2}$ and $\Delta_{2}{ }^{*}$ b) $\alpha=15^{\circ}, \alpha^{*}=30^{\circ}$ in system with coordinates $\mathrm{x}_{1}$ and $\mathrm{x}_{2}$

- Figure 1.4 presents the transformation of the unconditional area of existence from the field of independent variables $\Delta_{1}, \Delta_{1}{ }^{*}, \Delta_{2}$ and $\Delta_{2}{ }^{*}$ for output profile angles $\alpha=15^{\circ}$ and $\alpha^{*}=30^{\circ}$, to the field of independent shift coefficients of the instrument $\mathrm{x}_{1}$ and $\mathrm{x}_{2}$. The implemented areas by the ,(1.15) method of generalized parameters, but transformed into a coordinates system $\mathrm{x}_{1}$ and $\mathrm{x}_{2}$, allow a comparative analysis of the feasibility of a gear to be carried out.

The general System, which describes the limitations of the unconditional area of existence of an asymmetric profile and the method of generalized parameters in the presence of joint interference between the opposite involutes is:

$$
\mid \begin{aligned}
& \varepsilon_{\alpha}^{*}>1 ; \varepsilon_{\alpha}>1 \\
& \alpha_{p 1}>0 ; \alpha_{p 2}>0 \text {, using }\left(\operatorname{inv} \Delta_{1,2}+i n v \Delta_{1,2}^{*}\right)<\frac{2 . \pi}{z_{1,2}} \\
& \alpha_{p_{1}}+\alpha_{L_{1}}>0 ; \alpha_{p_{2}}+\alpha_{L_{2}}>0, \\
& \text { using }\left(\operatorname{inv} \Delta_{1,2}+i n v \Delta_{1,2}^{*}\right)>\frac{2 . \pi}{z_{1,2}}
\end{aligned}
$$

and additional conditions:

$$
\alpha<\alpha^{*} ;\left(\alpha+\alpha^{*}\right) \leq \frac{\pi}{2} ; S_{a 2}^{*}=\text { var }
$$

This is an Open Access article distributed under the terms of the Creative Commons Attribution Licence

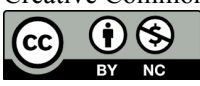

\section{References}

[1] Bulgakov E.B., "Theory of involute gears", Moscow, "Engineering", 1995.

[2] Bulgakov E.B., and Kapelevich A. L., Reducer aviation turboprop TB7-117, Moscow, Journal of Mechanical Engineering, 2000, № 11.

[3] Bulgakov E.B. and Dorofeev VL., 'Computer design of involute gears in generalizing parameters", Conversion in Engineering, 2002.

[4] Litvin F.L., "Development of Gear Technology and Theory of Gearing", University of Illinois, Chicago. National Aeronautics and Space Administration, Lewis Research Center, December 1997, NASA RP-1406.

[5] Yang Shyue-Cheng, "Mathematical model of a helical gear with asymmetric involute teeth and its analysis", Springer - Verlag, 003-2033-z

London, pp.448-456, Limited 2004, DOI 10.1007/s00170-

[6] Yang Shyue-Cheng, "Study on an internal gear with asymmetric involute teeth", Mechanism and Machine Theory ELSEVIER, pp. 977-994, October 2006, 0094-114X/\$.

[7] G. Mallesh, V. B. Math, Ashwij, Prabodh Sai Dutt R, Rajendra Shanbhag, "Effect of Tooth Profile Modification In Asymmetric Spur Gear Tooth Bending Stress By Finite Element Analysis", 14th National Conference on Machines and Mechanisms, NIT, Durgapur, India, December 17-18, 2009,pp.62-67,NaCoMM2009- ASMG18.

[8] G. Mallesh, V B Math, Gajanan, Uttesh, Sridhar, "Estimation of Critical Section and Bending Stress Analysis for Asymmetric Spur Gear Tooth" 14th National Conference on Machines and Mechanisms, NIT, Durgapur, India, December 17-18, 2009, pp.107-112,NaCoMM-2009- ASMG30.

[9] Karpat F., Çavdar K., Babalik C. F., "Computer Aided Analysis of Gears with Asymmetric Teeth", Uludağ Üniversitesi Mühendislik Mimarlık Fakültesi Dergisi, Cilt 9, Sayı 1, 2004, pp.123-131.

[10]Chira F., Dascalescu A., Tisan V., Stoicovici D., "The Study of the Stress and Displacements at the Direct Asymmetric Gears in Relation with the Coefficient of Asymmetry Using the Finite Elements Method", Annals of the Oradea University, Fascicle of
Management and Technological Engineering, Volume VII (XVII), 2008, pp. 1280-1286.

[11]Chira F., Banica M., "Algoritm si Program de Calcul Pentru Determinarea Sectiunii de Incastrare a Dintelui Evolventic Asimetric", Fascicle of Management and Technological Engineering, pp. 155-160.

[12]Chira F., Banica M., Stoicovici D., "The Influence of the Pressure Angles on the Transmission Error of the Asymmetric Gears" Annals of the Oradea University, Fascicle of Management andTechnological Engineering, Volume VI (XVI), 2007, pp. 13601365.

[13]Chira F., Tisan V., Dascalescu A.,"Modeling of the Asymmetric Gears Using Applications in Matlab and Autolisp", Annals of the Oradea University, Fascicle of Management and Technological Engineering, Volume VI (XVI), 2007, pp. 1366-1371.

[14]Karpat F., Çavdar K., Babalik C. F., "Asimetrik Evolvent Profilli duz Dışlılerin Boyutlandırılması ve Geometrik Modellerinin Oluşturulması", Uludağ Üniversitesi Mühendislik - Mimarlık Fakültesi Dergisi, Cilt 9, Sayı 1, 2004, pp.111-121.

[15]Di Francesco G., Linari M., Marini S., "Sistema di Modellazione ad Elementi Finiti per Ingranaggi a Fianchi Asimmetrici", Dipartimento di Ingegneria Meccanica e Industriale, Università degli Studi di Roma Tre, Italia, July 2016. 